\title{
Electrical Discharge Machining of Silicon Carbide Ceramic of Plane Processing
}

\author{
Geng Qidong', Li Chunyan² \\ ${ }^{2}$ School of Mechanical Engineering, Yancheng Institute of Technology, Yancheng, 224051, China
}

\begin{abstract}
Silicon carbide (SiC) has high specific stiffness, high thermal conductivity, and a low thermal deformation coefficient, making it highly applicable in the aeronautic and astronautic industries. However, the beneficial properties of high hardness and high strength cause problems in shaping SiC blanks. Electrical discharge machining (EDM) is a popular unconventional machining process for producing hard and brittle materials. An experimental investigation was conducted on the improved technologies of EDM. A good surface was obtained through plane processing using graphite as an electrode.
\end{abstract}

Keywords: electric discharge machining, array electrode, silicon carbide, plane processing

\section{Introduction}

Silicon carbide ( $\mathrm{SiC}$ ) is a non-oxide ceramic. It is widely used in water pumps, heat exchangers, bearings, and space telescopes [1, 2]. It possesses excellent properties, such as oxidation resistance, high mechanical strength at elevated temperature, high hardness, high corrosion resistance, high thermal conductivity, and high thermal shock resistance [3-6]. However, $\mathrm{SiC}$ ceramics have grinding difficulties due to their hard and brittle features. In traditional machining, diamond grinding is one of the most commonly used techniques for $\mathrm{SiC}$ ceramic blanks, but it is costly and inefficient [7-11]. Furthermore, $\mathrm{SiC}$ ceramics induce force damage and severe tool wear in diamond grinding [3, 12]. Electrical discharge milling is a promising and economical technique for to grind $\mathrm{SiC}$ ceramic blanks [13]. However, using this method to machine a large surface area on ceramics is inefficient [14, 15].

This paper uses array graphite as the tool electrode to machine $\mathrm{SiC}$ ceramics using electrical discharge plane machining (EDPM) [13]. The process employs the pulse generator used in EDPM and uses a water-based emulsion as the high-speed and pressure machining fluid [16]. In the process, the electrode has a plane movement, and the movement of the workpiece is controlled by a computer numerically controlled (CNC) platform. This procedure can effectively machine a large surface area on SiC ceramics. The effects of tool polarity, translational motion speed, and rushing speed on the machining performance are investigated.

\section{Principle for EDM Plane Processing of SiC Ceramics}

The principle of electrical discharge machining (EDM) plane processing is shown in Fig. 1. The workpiece and the tool are connected to the positive and negative poles of the pulse generator, respectively. The workpiece moves along the given route. Its path can be circular or follow a straight line. The movement can be realized through the X-Y platform. Usually, the workpiece is mounted onto a numerically controlled (NC) platform. The movement of the tool is identical to that of the workpiece. However, the trip is short. The tool is in array form and comprises many small pieces. The gap between the workpiece and tool is adjusted by the microfeeding system. It is a common feeding system, but not a servo system; thus, it is easy to implement. The machining fluid is a water-based working liquid. Sometimes, a water-based emulsion with numerous particles is used.

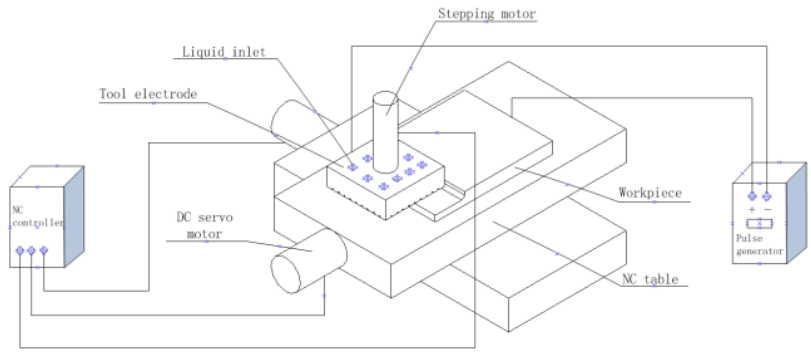

Figure 1: Schematic experimental setup for EDM plane processing

During machining, the tool moves on a short plane and is fed by a step motor. The $\mathrm{SiC}$ ceramic workpiece is fed towards the tool driven by a NC table. The machining fluid is flushed into the gap by the tubes. As the tool approaches the workpiece and the distance between a block of the tool and the workpiece reaches the discharge gap, electrical discharges are produced. During the pulse on-time, a plasma channel grows and is often accompanied by electrolysis. Numerous vapor bubbles form around this channel. The plasma can instantaneously reach a high temperature and pressures the EDM in conducting advanced ceramics [17]. Under this condition, the SiC ceramic is removed. During machining, the machining fluid is flushed into the gap from the inner part of the tool, the chips are flushed away easily, and the workpiece is cooled quickly, which stabilizes the processing. To improve machining efficiency, a large electrode was designed. The EDM plane processing uses graphite for the electrode and is manufactured easily. However, other electrode materials, such as red copper or iron, are large due to their density, making them unsuitable for larger electrodes. The form of the electrode is array and cross-shaped. The machining liquid flows from the inside of the electrode through many hoses along the cross rail, and the effect is good. The EDM plane processing uses graphite for the electrode, and the resistance to the abrasion of the graphite electrode is lower than that of the copper or steel electrode. In addition, using graphite as the tool material, the block 


\section{International Journal of Science and Research (IJSR) \\ ISSN (Online): 2319-7064}

Index Copernicus Value (2015): 78.96 | Impact Factor (2015): 6.391

electrode is shaped easily and has a low cost.

\section{Results and Discussion}

In the following experiments, the workpiece material is the $\mathrm{SiC}$ ceramic, the tool is a graphite array electrode, the tool is square-shaped, each small electrode is also square-shaped, the width is $1 \mathrm{~cm}$, the plane speed of the tool is $1 \mathrm{~m} / \mathrm{s}$, and the work fluid is a water-based emulsion with a $5 \%$ concentration. The weighing of the removed material or electrode wear was measured by an electronic analytical balance. Surface roughness was measured by a surface roughness tester. The microstructural observation of the $\mathrm{SiC}$ ceramic was conducted using a scanning electron microscope equipped with energy-dispersive spectrometer analysis. The accumulated debris was examined by microphoto after the spark had eroded the surface of the SIC ceramic with different parameters..

\subsection{Effect of polarity on the plane process performance}

The polarity effect often exists in electrical discharge machining, and EDM translational processing is not an exception. The effect of polarity on the MRR and the SR is illustrated in Figs. 2 and 3. As shown in Fig. 2, the MRR in the positive tool polarity is two times that with the negative tool polarity under the same conditions. Figure $X$ shows that the SR in the negative tool polarity is nearly two times that with positive tool polarity under the same conditions. These phenomena can be explained as follows. Under the same conditions of the electric field force effect, the speed of the electrons moving to the anode is higher than that of the positive ions moving to the cathode speed in the channel. This phenomenon occurs because the electron is light and has low inertia, easily obtaining a high speed in a short time. However, the positive ion is large, has high inertia, and encounters difficulty in obtaining a high instantaneous speed. Therefore, the MRR is high in the positive tool polarity. Additionally, an important reason is that the water-based working liquid is used in plane processing and has good conductivity, increasing the size of the discharge gap. In the positive tool polarity, the speed of the electron is fast and easily reaches the workpiece surface; thus, MRR is high. However, in negative polarity, the acceleration of the positive ions is low and does not easily reach the workpiece surface; thus, the material removal rate is low.

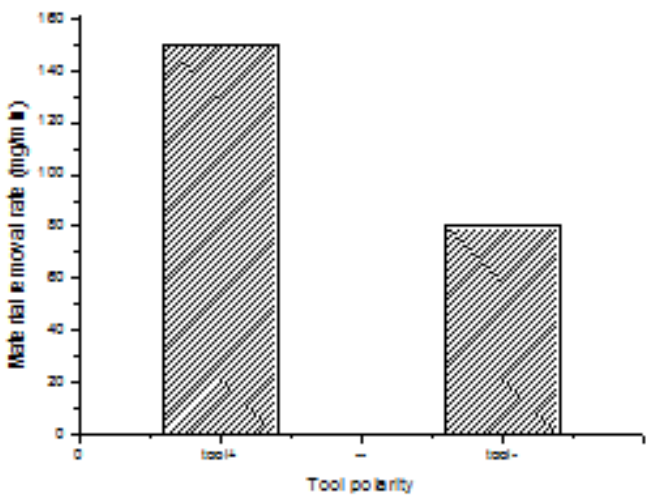

Figure 2: Effect of polarity on MRR

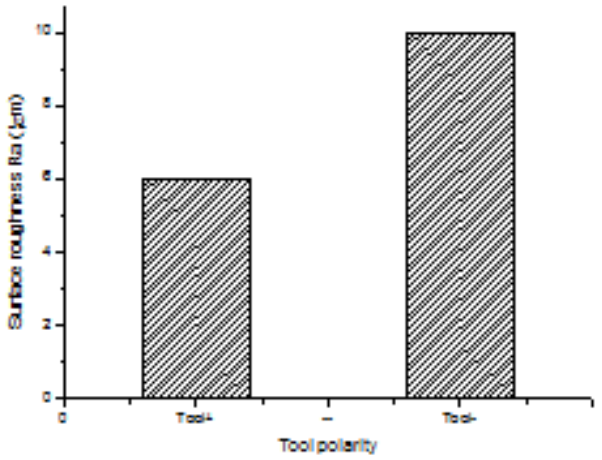

Figure 3: Effect of polarity on SR

\subsection{The effect of electrode translational motion speed on the plane process performance}

The effect of eletrode translational speed on MRR and SR is illustrated in Figs. 4 and 5. The experimental results show that the MRR increases and the SR decreases with the increase of translational velocity. This trend occurs because the discharge gap between the positive and negative electrodes shifts when the tool rotation speed increases and the discharge point moves frequently in EDM. It reduces the ratio of arc discharge and short circuit with the increase of translational speed. The inhibition of discharge concentration, abnormal arc discharge, and short circuit phenomenon occurred. This inhibition increases and extends the workpiece area of the role in single pulse; the discharge energy is spread out to decrease the discharge crater depth and the surface roughness.

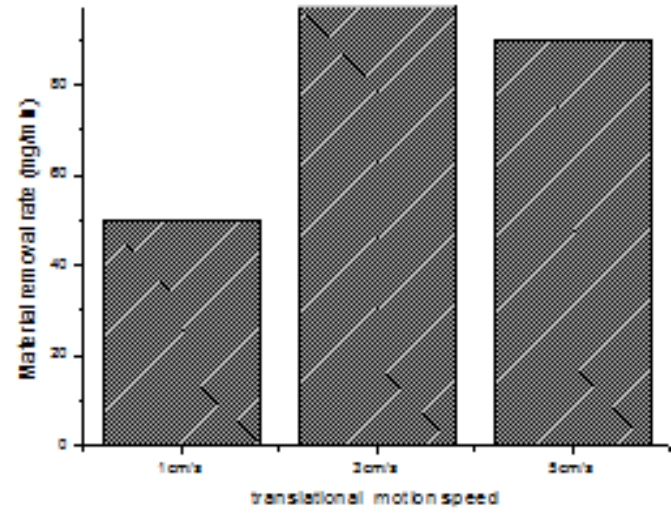

Figure 4: Effect of electrode translational motion speed on MRR

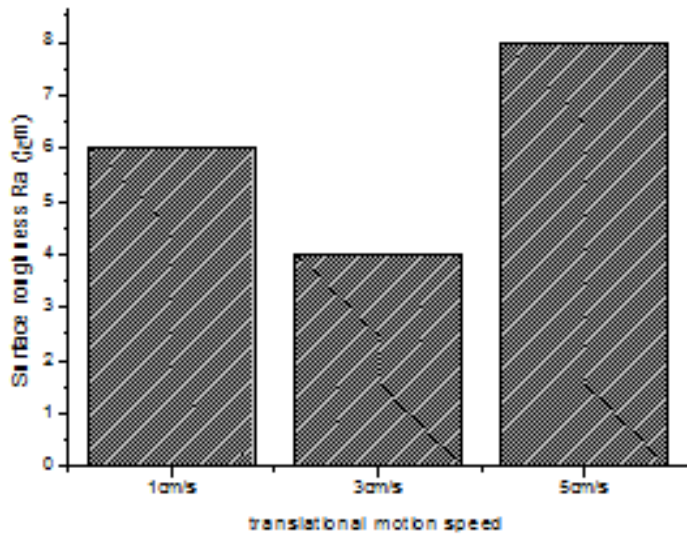

Figure 5: Effect of electrode translational motion speed on SR

Volume 6 Issue 7, July 2017 www.ijsr.net 


\section{International Journal of Science and Research (IJSR) \\ ISSN (Online): 2319-7064}

Index Copernicus Value (2015): 78.96 | Impact Factor (2015): 6.391

\subsection{Effect of speed on the plane process performance}

Dielectric fluid used in EDM machines provide important functions in the EDM process. The fluid controls the sparking gap spacing between the electrode and workpiece, cools the heated material to form the EDM chip, and removes the EDM chips from the sparking area. The EDM chips are collected at different rushing speeds, and the following photographs are obtained under scanning electron microscopy (SEM). Figures 6 to 9 show that the surface is good under high-speed liquid. The high rushing speed is good for chip removal and discharge, and the MRR is high. The microscope was is obtained under different rushing speeds. Figure 9 shows that the speed is small; thus, the spark discharge is local. Compared with the previous figure, the discharge of this surface is uniform, and the surface quality is better.

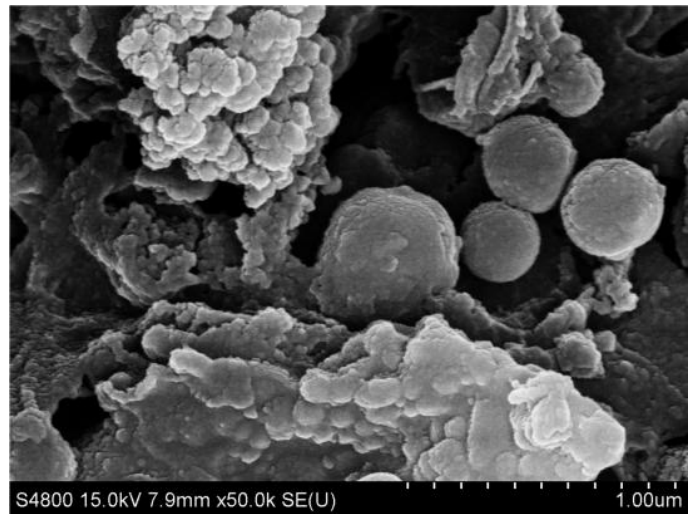

Figure 6: SEM image of EDM debrits in low-speed rushing

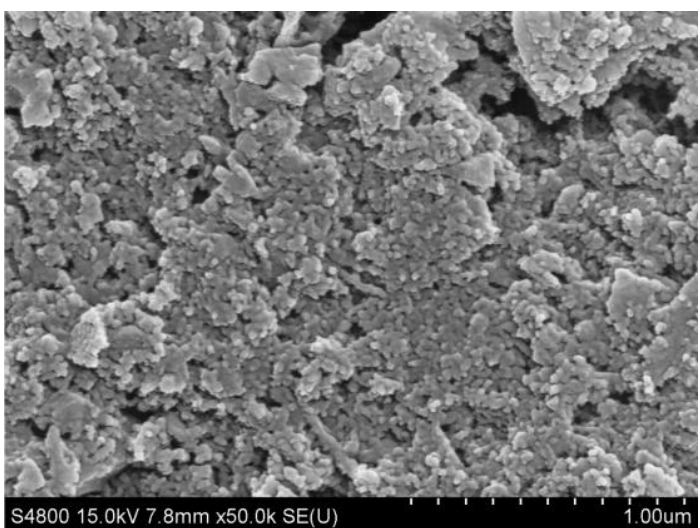

Figure 7: SEM image of EDM debrits in high-speed rushing

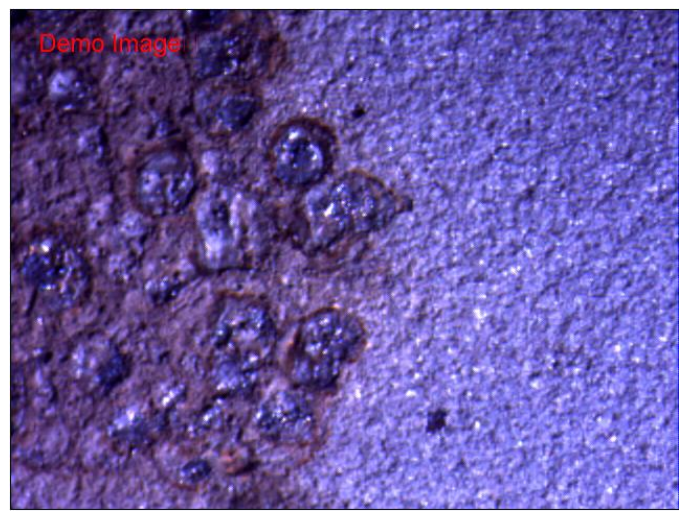

Figure 8: Microscope photo of the workpiece in low-speed rushing

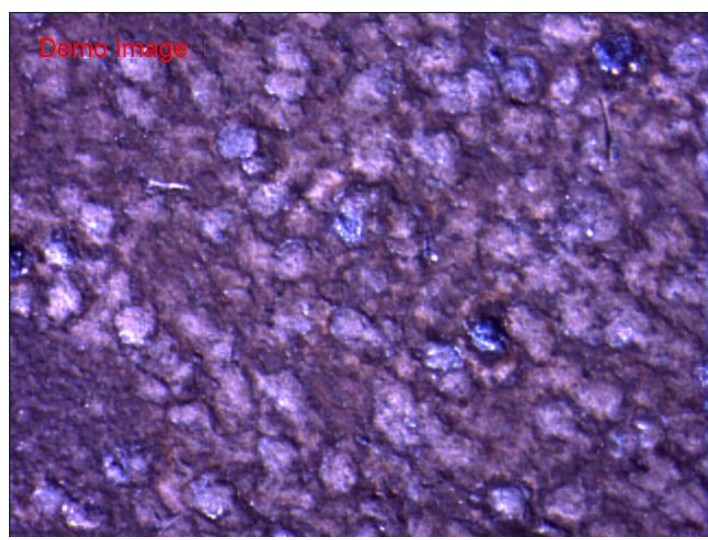

Figure 9: Microscope photo of workpiece in high-speed rushing

\section{Conclusions}

a) Using graphite as an electrode, the $\mathrm{SiC}$ ceramics can be easily machined by EDM. The process shows high MRR.

b) Positive polarity for the tool electrode should be used in large plane machining

c) A suitable translational speed is good for spark discharge machining.

d) Using high-speed and high-pressure liquid improves surface quality.

\section{References}

[1] Zhang, Y., et al., " Large-scale fabrication of lightweight $\mathrm{Si} / \mathrm{SiC}$ ceramic composite optical mirror," Materials Letters, 58(7-8), pp. 1204-1208, 2004.

[2] Dai, Y.T., et al., "Subsurface properties of ceramics for lightweight mirrors after ELID grinding, ” Jsme International Journal Series C-Mechanical Systems Machine Elements and Manufacturing, 47(1, pp 66-71,2004.

[3] Kasuga, H., et al., "Investigation on mirror surface grinding characteristics of $\mathrm{SiC}$ materials,"Journal of Ceramic Processing Research, 10(3), pp. 351-354, 2009.

[4] Chen, M.H., et al., "Application of reaction sintering to the manufacturing of a spacecraft combustion chamber of SiC ceramics,"Journal of Materials Processing Technology, 129(1-3), pp. 408-411, 2002.

[5] Yoshida, K., et al., "Mechanical properties of unidirectional and crossply $\mathrm{SiCf} / \mathrm{SiC}$ composites using $\mathrm{SiC}$ fibers with carbon interphase formed by electrophoretic deposition process," Progress in Nuclear Energy, 82,pp. 148-152., 2015.

[6] Rudneva, V.V., G.V. Galevsky, and N.A. Kozyrev, "Silicon nano-carbide in strengthening and ceramic technologies," Vi International Scientific Practical Conference on Innovative Technologies and Economics in Engineering,. 91,2015.

[7] Shih, A.J., "An experimental investigation of rotary diamond truing and dressing of vitreous bond wheels for ceramic grinding,"International Journal of Machine Tools \& Manufacture, 40(12), pp. 1755-1774,2000.

[8] Huang, S.T., et al., "A study on chip shape and chip-forming mechanism in grinding of high volume fraction $\mathrm{SiC}$ particle reinforced Al-matrix composites," 
International Journal of Advanced Manufacturing Technology, 80(9-12),p p. 1927-1932,2015.

[9] Xie, J., et al., "Study on ductile-mode mirror grinding of $\mathrm{SiC}$ ceramic freeform surface using an elliptical torus-shaped diamond wheel, " Journal of Materials Processing Technology,. 222, pp. 422-433,2015.

[10] Chao, C.L., et al., "Precision grinding of tungsten carbide mold insert for molding of sub-millimeter glass aspheric lenses," International Conference on Optics in Precision Engineering and Nanotechnology (Icopen2013), 8769, 2013.

[11] Wang, X. and X. Zhang, “ Theoretical study on removal rate and surface roughness in grinding a RB-SiC mirror with a fixed abrasive," Applied Optics 48(5),pp. 904-910,2009.

[12] Liu, Y.H., et al., “An experimental investigation for electric discharge milling of $\mathrm{SiC}$ ceramics with high electrical resistivity, "Journal of Alloys and Compounds,. 472(1-2), pp. 406-410,2009.

[13] Kimura, A., et al., " Fundamental study on multi-wire EDM slicing of $\mathrm{SiC}$ by wire electrode with track-shaped section, " Proceedings of the Seventeenth Cirp Conference on Electro Physical and Chemical Machining (Isem), 6: pp. 232-237, 2013.

[14] Dong, Z. and H. Cheng, "Study on removal mechanism and removal characters for $\mathrm{SiC}$ and fused silica by fixed abrasive diamond pellets, " International Journal of Machine Tools and Manufacture, 85, pp. 1-13,2014.

[15] Pay Jun, L., et al., “Effect of Different Dielectric Fluids on Micro EDM of Low Conductivity Ceramic Material RB-SiC, ” Advanced Materials Research, 565,pp. 529-34,2012.

[16] Yoo, H.K., et al., "Micro-electrical discharge machining characteristics of newly developed conductive SiC ceramic," Ceramics International, 41(3),pp. 3490-3496,. 2015.

[17] Zhao, Y., M. Kunieda, and K. Abe, "Study of EDM cutting of single crystal silicon carbide," Precision Engineering,38(1),pp. 92-99,2014. 